\title{
ENSINO NA GRADUAÇÃO E PRÁTICA PROFISSIONAL DE NUTRICIONISTAS SUPERVISORAS DE ESTÁGIO EM SERVIÇOS DE ALIMENTAÇÃO
}

\author{
Joice Trindade Silveira ${ }^{1}$ \\ Karina Wermuth ${ }^{2}$ \\ Ingrid Jesien ${ }^{3}$
}

\section{RESUMO}

O objetivo deste trabalho foi investigar a compatibilidade entre o ensino na graduação e a prática profissional de nutricionistas supervisoras de estágio em serviços de alimentação. 0 trabalho foi realizado no curso de Nutrição da Universidade Federal do Pampa com as seguintes etapas: 1) Entrevista com as nutricionistas supervisoras de estágio na área de alimentação coletiva; 2) Análise dos conteúdos presentes em sete planos de ensino relacionados à área; 3) Avaliação da compatibilidade entre o ensino e a prática. Participaram quatro nutricionistas, e foi observada uma compatibilidade parcial entre os conteúdos apresentados nos planos de ensino e as atividades profissionais relatadas. Os conteúdos que não foram citados, no entanto, são exigidos por legislações profissionais. Diferentemente da prática, a abordagem teórica dos conteúdos mostrou-se mais técnica. Sugere-se, portanto, a ampliação dessa abordagem, considerando a operacionalização dos conhecimentos como forma de aproximá-los da prática profissional.

Palavras-chave: Alimentação coletiva. Ensino superior e prática. Estágio em Nutrição. Serviços de alimentação.

\section{Como citar este documento - ABNT}

SILVEIRA, Joice Trindade; WERMUTH, Karina; JESIEN, Ingrid. Ensino na graduação e prática profissional de nutricionistas supervisoras de estágio em serviços de alimentação. Revista Docência do Ensino Superior, Belo Horizonte, v. 9, e012346, 2019. DOI: https://doi.org/10.35699/2237-5864.2019.12346.

Recebido em: $15 / 04 / 2019$ Aprovado em: 21/05/2019 Publicado em: 02/09/2019

\footnotetext{
${ }^{1}$ Universidade Federal de Pampa (Unipampa), Campus Itaqui, RS, Brasil. ORCID ID: https://orcid.org/0000-0001-5845-7503. E-mail: joicetsilveira@gmail.com.

2 Universidade Federal de Pampa (Unipampa), Campus Itaqui, RS, Brasil. ORCID ID: https://orcid.org/0000-0003-3329-6672. E-mail: karinawermuth.kw@gmail.com.

${ }^{3}$ Universidade Federal de Pampa (Unipampa), Campus Itaqui, RS, Brasil. ORCID ID: https://orcid.org/0000-0003-2151-2147. E-mail: ingridjesien@hotmail.com.
} 


\section{ENSEÑANZA EN LA GRADUACIÓN Y PRÁCTICA PROFESIONAL DE NUTRICIONISTAS SUPERVISORAS DE PASANTÍA EN SERVICIOS DE ALIMENTACIÓN}

\section{RESUMEN}

El objetivo de este estudio fue investigar la compatibilidad entre enseñanza en la graduación y práctica profesional de nutricionistas supervisoras de pasantía en servicios de alimentación. El trabajo fue hecho en el curso de Nutrición de la Universidad Federal del Pampa y las etapas fueron las siguientes: 1) Encuesta con las nutricionistas supervisoras de prácticas curriculares en los servicios de alimentación; 2) Análisis de los temas de siete planes de enseñanza que tenían relación con el área; 3) Evaluación de la compatibilidad entre la enseñanza y la práctica. Respondieron a la encuesta cuatro nutricionistas y fue observada una compatibilidad parcial entre los planes y las actividades profesionales. Hubo temas no relatados en las encuestas, aunque son requeridos por las legislaciones. La práctica se mostró distinta de la teoría, que tuvo un abordaje más técnico. Se sugere, así, una ampliación del abordaje de los temas como una forma de aproximarlos de la práctica.

Palabras clave: Alimentación colectiva. Ensenãnza superior y práctica. Pasantías en Nutrición. Servicios de alimentación.

\section{TEACHING IN GRADUATION AND PROFESSIONAL PRACTICE OF NUTRITIONISTS WHO SUPERVISE INTERNSHIPS AT FOOD SERVICES}

\section{ABSTRACT}

The aim of this study was to investigate the compatibility between teaching in graduation and professional practice of nutritionists who supervise curricular internships at food services. The study was conducted at the Nutrition course of Federal University of Pampa through the following steps: 1) Interview with the nutritionists who had supervisioned curricular internships at food services; 2) Analysis of the subjects of teaching programs from seven courses related with the area of interest; 3) Evaluation of compatibility between subjects of these courses and professional practice. Four nutritionists participated, and a partial compatibility between the subjects and the professional activities was observed. Some subjects were not mentioned, although they are required by professional legislation. Unlike the practice, the theory approach was more technical. It is suggested, hence, to broaden the subject approach, considering the operationalization of knowledge as a way to bring them closer to professional practice.

Keywords: Collective Feeding. Internships at Nutrition. Food services. Higher education and practice. 


\section{INTRODUÇÃO}

No ensino superior é frequente a discussão sobre a necessidade de aproximação entre o ensino e a prática profissional. Desde a Lei de Diretrizes e Bases para a Educação Nacional (BRASIL, 1996), há referência sobre a necessidade de estimular o conhecimento dos problemas reais da sociedade, e uma das formas mais utilizadas pelas instituições de ensino para fazer essa aproximação são os estágios curriculares. Na tentativa de dar uma resposta mais adequada às necessidades da população, na área da saúde tem sido utilizado o processo de integração ensino-serviço (ALBURQUERQUE et al., 2008; SILVA; LIMA SANTOS; DE AMORIM, 2018), porém, na área de alimentação coletiva, apesar de haver trabalhos com egressos que avaliam seu ensino anterior (EMILAURA et al., 2003; RODRIGUES; PERES; WAISSMANN, 2007; FEIX; POLL, 2015) não há estudos sobre como se dá a aproximação entre teoria e prática.

A área de alimentação coletiva é uma das três grandes áreas do curso de Nutrição. Como o próprio nome sugere, ela é responsável pelas atividades de alimentação e nutrição realizadas em serviços de alimentação - sejam eles terceirizados, de auto-gestão, de alimentação escolar e do trabalhador, entre outras (CFNa, 2018). Ela pode ser considerada a área mais técnica dentro da nutrição - com diversas atividades administrativas e burocráticas a ser cumpridas - e é a que mais se aproxima do mercado. Atuam nessa área cerca de um terço dos nutricionistas do Brasil (CFNb, 2018).

O curso de Nutrição da Universidade Federal do Pampa (Unipampa) iniciou suas atividades em 2010, tendo seis turmas de nutricionistas formados até o momento. De acordo com o Projeto Pedagógico do Curso, os componentes curriculares mais voltados para a área de alimentação coletiva iniciam no segundo semestre, com Técnica Dietética, e seguem adiante com Higiene e Legislação de alimentos, Alimentação Coletiva, Gestão de Unidades de Alimentação e Nutrição, até chegar nos estágios curriculares no sétimo semestre (UNIPAMPA, 2012).

O estágio na área de alimentação coletiva é obrigatório para os cursos de Nutrição em todo o país (DCN, 2001). Além do professor orientador, o estudante deve contar com a presença do(a) nutricionista supervisor(a) do local de estágio (DCN, 2001; CFN, 2008), que realiza esse trabalho de forma voluntária. O Código de Ética do Nutricionista (CFNc, 2018, p. 23) estimula e orienta a atividade:

Art. 66. É direito do nutricionista exercer a função de supervisor/preceptor de estágios em seu local de trabalho.

Art. 67. É direito do nutricionista delegar atribuições privativas do nutricionista a estagiário de nutrição, desde que sob a supervisão direta e responsabilidade do profissional, de acordo com o termo de compromisso do estágio. 
Os estágios, além de beneficiarem diretamente o aluno - para muitos, é nessa etapa que se dá o primeiro contato com a prática profissional -, beneficiam também o serviço, pois levam atualizações científicas e permitem a divisão das tarefas diárias. Dessa forma, surgem os questionamentos: o ensino na área de alimentação coletiva está relacionado com a prática profissional? Como foi a formação das supervisoras de estágio? Como é o seu trabalho? Essas são questões importantes sobre a realidade dos diferentes tipos de serviço que podem enriquecer tanto o curso de Nutrição da Unipampa quanto os outros cursos no Brasil. O objetivo deste trabalho foi, além de conhecer, verificar a compatibilidade entre o ensino na graduação e a prática profissional de nutricionistas supervisoras de estágio na área de alimentação coletiva.

\section{METODOLOGIA}

Trata-se de uma pesquisa qualitativa (MINAYO, 1996) realizada durante o ano de 2017. 0 trabalho consistiu de três etapas: 1a) Foi investigado o trabalho e as atividades realizadas pelas nutricionistas supervisoras de estágio em alimentação coletiva; 2a) Foram analisados os conteúdos presentes nos sete planos de ensino dos componentes curriculares envolvidos com a área de alimentação coletiva. Os planos foram solicitados aos docentes responsáveis por cada componente curricular; 3a) Foram comparadas as atividades desenvolvidas pelas nutricionistas e os conteúdos indicados nos planos de ensino.

Para a primeira etapa da pesquisa foi utilizado um instrumento constituído de duas partes: a primeira continha um questionário com informações pessoais e profissionais - nome, universidade e ano de formatura, pós-graduação, local de trabalho atual e número de alunos da Unipampa supervisionados até o momento. Na segunda parte do instrumento, havia um roteiro com as seguintes questões:

Sobre a sua formação na universidade:

1) Você poderia falar um pouco sobre a sua formação em Nutrição?

2) Como você avalia a formação que você teve na universidade para a área de alimentação coletiva? Lembra quais eram as disciplinas ou quais os conteúdos que eram abordados? 0 que foi bom e o que faltou?

Sobre o trabalho na alimentação coletiva:

1) Você poderia falar um pouco sobre a sua trajetória profissional e como se deu a sua ida para a área de alimentação coletiva?

2) Como é um dia típico de trabalho seu? Quais são as suas atividades?

3) Você gosta do seu trabalho atual? Por quê?

4) Como você avalia o trabalho na área de alimentação coletiva? O que está bom e o que precisa melhorar?

Sobre os estágios:

1) Quais os conhecimentos prévios necessários para a realização da prática profissional de nutrição na Unidade de Alimentação e Nutrição (UAN)? 
Foram convidadas a participar todas as 15 nutricionistas que orientaram estágio curricular durante os anos de 2014, 2015 e 2016 na Universidade Federal do Pampa. Inicialmente foi feito um contato inicial via telefone com cada uma das nutricionistas, a fim de explicar a pesquisa e verificar o seu interesse em participar. Após esse primeiro contato, as questões foram enviadas de forma on-line para todas as nutricionistas que aceitaram participar. Após o período de uma semana, àquelas nutricionistas que não responderam foi enviado um segundo e último e-mail sobre a pesquisa. Aguardou-se mais uma semana pelas respostas e encerrou-se a coleta de dados.

As respostas escritas foram impressas exatamente da forma com que as nutricionistas responderam. Uma das nutricionistas enviou as respostas em áudio via aplicativo, porém, os pesquisadores optaram por incluir a resposta na pesquisa. Esta foi degravada e, posteriormente, impressa. A partir desses documentos iniciais, foi utilizada a técnica de análise de conteúdo (BARDIN, 1979). Procurou-se identificar, nas diferentes questões, quais atividades eram realizadas pelas nutricionistas nas suas rotinas de trabalho.

O projeto foi aprovado pelo Comitê de Ética em Pesquisa da Universidade Federal do Pampa (CAAE: 79951717.2.0000.5323).

\section{RESULTADOS}

Participaram da pesquisa quatro nutricionistas, as quais foram identificadas como N1, N2, N3 e N4. As respostas escritas foram mais sucintas e objetivas do que a resposta recebida em áudio, que foi mais detalhada.

Todas as nutricionistas formaram-se em instituições particulares localizadas em diferentes regiões do Estado do Rio Grande do Sul, como Campanha, Missões, Vale dos sinos e Central; uma delas possuía pós-graduação na área clínica. Três nutricionistas formaram-se entre 2002 e 2005 (média de 13,7 anos de formadas) e uma formou-se em 1987 (30 anos de formada no momento da pesquisa). Em relação à área de trabalho, duas trabalham em Unidades de Alimentação e Nutrição (UAN) do tipo terceirizada, sendo uma voltada à alimentação do trabalhador, e outra, ao público universitário; e duas trabalham em UAN hospitalar do tipo auto-gestão. O número de alunos supervisionados durante o estágio variou de um a oito alunos por ano. Uma das entrevistadas atuava no município de realização da pesquisa e as demais em cidades localizadas em municípios de 100 a $500 \mathrm{~km}$ de distância, nas regiões de fronteira entre Brasil e Uruguai e Brasil e Argentina.

Todas as nutricionistas referiram gostar do seu trabalho atual, como se percebe em suas falas, a seguir. N1: "Sim, me sinto feliz...", N2: "Gosto do meu trabalho atual... Eu adoro, não consigo me ver fazendo outra coisa", N3: "Gosto muito, me realizo com meu trabalho... Minha trajetória foi sempre cheia de desafios... Mas quando avalio gosto do que vejo... E o 
que consegui e consigo realizar... O resultado positivo do meu trabalho...", N4: "Adoro o meu trabalho. Me realizo fazendo o que eu gosto".

A entrevistada N4 afirmou que é necessário ter agilidade e perfil para a função. A nutricionista da unidade hospitalar (N1) caracterizou sua atividade como gratificante devido à contribuição para a recuperação dos pacientes e à grande aceitação e satisfação dos pacientes com relação à dieta. A nutricionista N2 avaliou o seu trabalho como bom e relatou também que é muito "puxado", pois, devido à grande responsabilidade com a equipe e com os consumidores, "acaba sendo estressante".

Sobre as atividades desenvolvidas, N2 relata:

"Eu chego e já vou direto pra cozinha [...] passar em todas as áreas [...] verificar [...] se a geladeira, se os freezers estão [...] com as temperaturas que deveriam estar [...] no andamento do arroz, do feijão, da carne [...] verificar se a atividade da cozinheira está correta, se a cozinha está organizada" (Entrevistada N2).

Ela ainda cita que verifica a organização do salão e a execução das sobremesas e das saladas para que esteja tudo pronto antes do início do horário de abertura do restaurante para o almoço, às $11 \mathrm{~h}$. Ela organiza o trabalho de forma que cada funcionário tenha a sua responsabilidade, tanto de produção de alimentos quanto de atividades mais burocráticas, por exemplo: quem recebe os hortifrutigranjeiros é o responsável pela produção das saladas; enquanto quem afere as temperaturas de todos os alimentos produzidos e, posteriormente, preenche as planilhas correspondentes é uma das cozinheiras. A nutricionista explica o modo de fazer e supervisiona a execução das tarefas.

Em outra unidade, localizada dentro de um hospital, a nutricionista N1 relata que a sua primeira atividade é ir à cozinha e à copa e conversar com os colaboradores, a fim de verificar o andamento da produção. Em seguida efetua atividades administrativas, como os pedidos de gêneros alimentícios e materiais necessários para os demais turnos e para o próximo dia. Depois retorna à cozinha, avalia o cardápio e verifica a necessidade de modificações. Relata também que faz o acompanhamento e a fiscalização dos setores quanto ao preenchimento de planilhas, às tarefas dos colaboradores, ao recebimento de gêneros, ao preparo das refeições, à higienização da unidade, e, ainda, faz as atividades que não são diárias, como escalas de trabalhadores e cálculos de custos.

A nutricionista N2 relatou que já passou por situações difíceis. Por ausência de funcionários, teve que assumir funções de auxiliar de limpeza e cozinheira dentro da UAN e, em outra ocasião, por desconhecimento do sistema, já ficou desabastecida de alimentos básicos, como arroz e feijão. Ela relata que tenta, hoje, utilizar isso como aprendizado e orientar cada funcionário sobre as suas responsabilidades: 
"[...] isso tudo também por falta... de um direcionamento do profissional, simplesmente larga o profissional ali e deixa ele andar com as próprias pernas... Tem que explicar para as pessoas o que tu quer... Cada colaborador que entra, eu procuro acompanhar, procuro explicar o que que eu quero, porque simplesmente largar o profissional ali não tem como" (Entrevistada N2).

Conforme as nutricionistas, para a prática profissional é necessário que se tenha conhecimentos prévios sobre gestão de pessoas e administração de empresas - coordenar equipes, fazer pedidos de compras e resolver situações imprevistas. Em um dos relatos a nutricionista N2 traz a importância da prática:

"Eu, como aluna, me lembro que eu pensava: como vai ser? O que eu vou fazer? E eu acho que eles têm que praticar; a prática que vai me dar essa base para conseguir resolver situações... Olha, faltou comida!... Tu tem que estar preparado, mas acho que os professores deveriam fazer com que visitassem uma área, incentivar o estágio, incentivar o estágio sempre!" (Entrevistada N2).

Quando falado sobre as dificuldades, novamente surge o problema de conseguir mão de obra qualificada e as questões financeiras, como o bloqueio de compras e a remuneração do Sistema Único de Saúde (SUS) para as dietas especiais. Também foram citadas questões administrativas e jurídicas. Para resolver essas questões elas preferem entrar em contato com outros setores da empresa.

Os componentes curriculares (CC) obrigatórios relacionados à área de UAN foram: Técnica Dietética, Higiene e Legislação de Alimentos, Controle de Qualidade, Alimentação Coletiva, Gestão de Unidades de Alimentação e Nutrição, e Estágio Curricular em Unidades de Alimentação e Nutrição. O CC Complementar (não obrigatório) incluído foi o de Tópicos de Gastronomia Aplicados à Nutrição.

No Quadro 1, estão demonstrados os conteúdos integrantes do plano de ensino de cada componente curricular. A disciplina de estágio não possui conteúdos descritos no seu plano de ensino, por isso, foi incluído somente o objetivo do componente curricular. Os itens que estão em negrito foram citados nas respostas das nutricionistas.

Houve uma compatibilidade parcial entre os conteúdos descritos nos planos de ensino e as atividades práticas relatadas pelas nutricionistas. Parte dos conteúdos citados pelas nutricionistas estavam presentes nos planos de ensino e vice-versa. Porém, além dos conteúdos ("o que fazer") foram relatados pelas nutricionistas o "como fazer", isto é, a descrição detalhada da rotina dentro da UAN. Suas atividades envolviam a aplicabilidade dos conteúdos. 
Ensino na graduação e prática profissional de nutricionistas supervisoras de estágio em serviços de alimentação

Joice Trindade Silveira, Karina Wermuth, Ingrid Jesien

\begin{tabular}{|c|c|}
\hline \multicolumn{2}{|c|}{ Conteúdos dos planos de ensino } \\
\hline Técnica Dietética I - 20 seme & $\begin{array}{l}\text { Tópicos de Gastronomia Aplicados à Nutrição -- } \\
\text { Complementar }\end{array}$ \\
\hline $\begin{array}{l}\text { Fichas técnicas } \\
\text { Equivalência de pesos e medidas } \\
\text { Técnicas de pré-preparo e preparo } \\
\text { Índices e cálculos no preparo de alimentos } \\
\text { Leite e derivados } \\
\text { Princípios de seleção e coç̧ão } \\
\text { Carnes, ovos, hortaliças e frutas, cereais, } \\
\text { leguminosas, bebidas } \\
\text { Avaliação sensorial }\end{array}$ & $\begin{array}{l}\text { Histórico da gastronomia } \\
\text { Tipos de regras e serviços } \\
\text { Principais cuidados de higiene } \\
\text { Carnes; hortaliças } \\
\text { Garde manger } \\
\text { Cozinha para necessidades específicas - sem } \\
\text { glúten, sem lactose } \\
\text { Gastronomia hospitalar e infantil } \\
\text { Plano de marketing }\end{array}$ \\
\hline Higiene de Alimentos e Legislação - & \\
\hline $\begin{array}{l}\text { Segurança alimentar versus segurança dos } \\
\text { alimentos } \\
\text { Doenças transmitidas por alimentos } \\
\text { Órgãos vinculados à segurança de alimentos, } \\
\text { legislações sanitárias } \\
\text { Boas práticas: edificações, instalações, móveis e } \\
\text { utensílios; controle integrado de pragas e } \\
\text { vetores; abastecimento de água; manejo de } \\
\text { resíduos; manipuladores; matérias-primas, } \\
\text { ingredientes e embalagens; } \\
\text { armazenamento e distribuição dos alimentos; } \\
\text { armazenamento e transporte do alimento } \\
\text { preparado; exposição ao consumo; documentos, } \\
\text { registros e responsabilidade; atividade prática - } \\
\text { apresentação da aplicação do check list }\end{array}$ & $\begin{array}{l}\text { Histórico da qualidade } \\
\text { Qualidade: definições, princípios e importância } \\
\text { Ferramentas de qualidade } \\
\text { Qualidade dos alimentos: aspectos sensorial, } \\
\text { nutricional, higiênico-sanitário } \\
\text { responsabilidade socioambiental } \\
\text { Sistema 5S } \\
\text { Manual de boas práticas } \\
\text { Procedimentos operacionais padronizados } \\
\text { (POPs) } \\
\text { Normas e normalização - Série ISSO } 9000 \text { e } \\
22000\end{array}$ \\
\hline Alimentação Coletiva - 5o semestre & $\begin{array}{l}\text { Gestão de Unidades de Alimentação e Nutrição } \\
\qquad 60 \text { semestre }\end{array}$ \\
\hline $\begin{array}{l}\text { Planejamento físico-funcional }- \text { geral/setor } \\
\text { trabalho, setor educação, setor saúde (hospitais, }\end{array}$ & $\begin{array}{l}\text { Cardápios } \\
\text { Custos de cardápios - fixos e variáveis }\end{array}$ \\
\hline
\end{tabular}


Ensino na graduação e prática profissional de nutricionistas supervisoras de estágio em serviços de alimentação

Joice Trindade Silveira, Karina Wermuth, Ingrid Jesien

\begin{tabular}{|c|c|}
\hline $\begin{array}{l}\text { Alimentação escolar - legislações, planejamento } \\
\text { de cardápios, fichas técnicas, cálculos de custos, } \\
\text { qualidade nutricional, supervisão, teste de } \\
\text { aceitabilidade, plano anual de trabalho. } \\
\text { Segurança e saúde do trabalhador - princípios } \\
\text { de ergonomia, trabalho na UAN, uso de } \\
\text { equipamentos de proteção individuais (EPIs) e } \\
\text { coletivos (EPCs) por função } \\
\text { Educação nutricional em UAN }\end{array}$ & $\begin{array}{l}\text { Lucro; controle do desperdício } \\
\text { Teorias da administração e gestão da qualidade } \\
\text { Liderança, autoridade e motivação } \\
\text { Dimensionamento de recursos humanos } \\
\text { Recrutamento e seleção } \\
\text { Relações trabalhistas } \\
\text { Treinamentos e capacitações } \\
\text { Trabalho em grupos e resolução de conflitos } \\
\text { Qualidade em UAN }\end{array}$ \\
\hline \multicolumn{2}{|c|}{ Estágio Curricular em Unidades de Alimentação e Nutrição - 70 ou 8 semestre } \\
\hline $\begin{array}{l}\text { Objetivo geral: propiciar a vivência do processo de } \\
\text { enfermas com vista à alimentação segura nos asp } \\
\text { específicos: desenvolver no aluno a capacidade d } \\
\text { analisar o dimensionamento físico, funcional } \\
\text { capacidade de gestão de pessoas; planejar cardá }\end{array}$ & $\begin{array}{l}\text { ectos nutricionais e higiênico-sanitários. Objetivos } \\
\text { planejar, organizar, dirigir e controlar uma UAN; } \\
\text { organizacional de uma UAN; desenvolver a } \\
\text { ios, de acordo com as necessidades nutricionais } \\
\text { alidade. }\end{array}$ \\
\hline
\end{tabular}

Quadro 1 - Conteúdos do plano de ensino por componente curricular e sua citação nas entrevistas Fonte: quadro elaborado pelos autores, com base nos planos de ensino enviados pelos docentes.

\section{DISCUSSÃO}

Em relação à compatibilidade parcial observada entre os conteúdos dos planos de ensino e as respostas das nutricionistas, é necessário fazer algumas considerações. Alguns conteúdos, embora não tenham sido citados, são considerados conhecimentos básicos para os nutricionistas, pois são necessários de forma indireta. Quando a nutricionista relata que faz a "supervisão da produção de alimentos", está implícito que ela deve conhecer procedimentos básicos de cocção e transformação dos diferentes grupos alimentares - conhecimentos que estão presentes nos conteúdos de Técnica Dietética e Tópicos de Gastronomia. Além disso, entre as atribuições do nutricionista nessa área, estão tanto a implantação quanto a supervisão de atividades de pré-preparo, preparo, distribuição e transporte de refeições (CFN, 2008).

Situação semelhante foi observada no componente curricular de Higiene e Legislação. As leis sanitárias, como a RDC no 216 (BRASIL, 2004), ou a Portaria no 78/2009 (RIO GRANDE DO SUL, 2009), por exemplo, não foram citadas, mas seu conhecimento é essencial à formação 
do nutricionista. Este profissional tem a responsabilidade de elaborar o manual de boas práticas (CFNa, 2018), que é o documento no qual estão descritas as operações relacionadas à higiene de alimentos do estabelecimento (BRASIL, 2004) e pode assumir a responsabilidade técnica do serviço (CFNa, 2018), ou seja, pode responder legalmente sobre a qualidade sanitária dos alimentos.

Outros conteúdos não citados pelas nutricionistas, como relações trabalhistas e lucros, já foram descritos por outros autores como parte da atividade profissional (RODRIGUES; PERES; WAISSMANN, 2007). Esses conteúdos, assim como o dimensionamento de recursos humanos, também são citados na legislação profissional como atividades complementares do nutricionista (CFNa, 2018). Para planejar as disciplinas e os conteúdos em um projeto pedagógico de curso, é necessário que os docentes considerem as atribuições legais dos profissionais.

Neste trabalho observou-se que os conteúdos são apenas uma parte da atividade do nutricionista, pois, na prática, o que ocorre é a operacionalização do conhecimento. Para exemplificar, vamos usar o tópico de controle de temperaturas. Na sala de aula, supondo que o ensino seja guiado pela legislação, o aluno aprenderá quais são as faixas de temperatura adequadas (RIO GRANDE DO SUL, 2009). Porém, na prática, as nutricionistas relataram: "Verifico o preenchimento das planilhas (de temperatura)", logo, o que o estudante precisará saber é: em quais etapas do preparo devo medir a temperatura? Quais planilhas usar? Como ensinar os funcionários a usar o termômetro? O mesmo pode acontecer com o controle do desperdício, por exemplo. Os estudantes podem aprender quais são os valores de referência (VAZ, 2006), mas aprenderão como operacionalizar o processo de economia de recursos? Quem vai pesar os alimentos? Em que momento? Os conteúdos são necessários para a execução das atividades em condições normais, mas, talvez, estejamos ensinando somente os conteúdos, e não como usá-los no ambiente de trabalho.

Como sugestão, nos conteúdos que são relacionados à prática, poderiam ser evitadas abordagens somente teóricas. No amplo tema Gestão de Pessoas, por exemplo, pode-se esclarecer que estudar sobre diferentes teorias de gestão não é o mesmo que gerir um grupo de funcionários, assim como aprender sobre teorias de liderança não é o mesmo que aprender a liderar. As DCNs incluem, como habilidades específicas, que devem ser desenvolvidas no nutricionista, o planejamento, o gerenciamento e a avaliação de unidades de alimentação e nutrição (BRASIL, 2001).

Para o planejamento das aulas, inicialmente poderia ser feita uma investigação sobre as atividades das nutricionistas relacionadas a determinado conteúdo. Por exemplo, nos custos, além de saber quais as alternativas possíveis para a redução de custos, pode-se fazer com 
que o aluno planeje as modificações no cardápio de forma que o custo da matéria-prima seja reduzido. Situações-problema observadas nos estágios podem ser utilizadas de forma pedagógica, estudando como resolvê-las. Nos relatos das nutricionistas apareceram problemas como: o que fazer quando falta comida? Como orientar funcionários com baixa escolaridade? Esses mesmos problemas reais poderiam retroalimentar as disciplinas, ou seja, serem usados pelos professores para que os alunos possam refletir e preparar-se para resolver os problemas reais antes de ingressarem no estágio. Aprender como resolver cada situação envolve liderança, tomada de decisões, comunicação e outras habilidades que vão além do conteúdo (BRASIL, 2001).

Em sala de aula, podem ser incluídas metodologias ativas ${ }^{4}$. Além disso, como referência para a organização dos componentes curriculares, poderia ser usado o PBL (Problem Based Learning $)^{5}$ e suas variações. Considera-se importante que os professores também estejam atentos às $\mathrm{DCNs}^{6}$, pois nelas estão descritas outras competências ou habilidades que devem ser desenvolvidas na formação.

Para o planejamento das atividades, sugere-se que sejam consideradas as atribuições do nutricionista previstas nas legislações profissionais e educacionais, a prática profissional e o conhecimento científico presente no momento.

\section{CONSIDERAÇÕES FINAIS}

Este trabalho observou uma compatibilidade entre os conteúdos presentes no plano de ensino e a realidade do trabalho. Em relação aos conteúdos, há aqueles que são necessários implicitamente, aqueles que já foram relatados por outros autores como parte da atividade profissional e outros que estão presentes nas legislações profissionais. Cabe ao corpo docente uma avaliação constante sobre os temas pertinentes à formação.

No entanto, considera-se que a principal contribuição deste trabalho é demonstrar que essa compatibilidade pode ser parcial devido ao tipo de abordagem dos conteúdos. $O$ trabalho é

\footnotetext{
${ }^{4}$ Não há uma definição única e exclusiva sobre o termo metodologias ativas. Em geral elas se opõem aos métodos tradicionais de ensino quando estes são caracterizados por aulas do tipo palestra, na qual o aluno permanece de forma "passiva". As metodologias ativas colocam o aluno em atividade no centro do processo de aprendizagem. Os termos mais comumente associados às metodologias ativas são aprendizagem ativa (BONWELL; EISON, 1991), aprendizagem colaborativa, aprendizagem cooperativa (MILLIIS; COTTEL; JUNIOR, 1998) e aprendizagem baseada em problemas (Problem Based Learnig ou PBL) (ALBANESE; MITCHELL, 1993). Destaca-se que o PBL é um método abrangente de ensino que necessita de uma modificação curricular e uma compreensão aprofundada do fenômeno pelos professores.

${ }^{5}$ Para um melhor aprofundamento sobre o tema, consultar os trabalhos de Albanese e Mitchell (1993) e Ravitz (2009).

${ }^{6}$ Competências e habilidades descritas pelas DCNs: tomada de decisões, comunicação, administração e gerenciamento, liderança, educação permanente e atenção à saúde (BRASIL, 2001).
} 
prático, baseado no "como fazer", e o conteúdo é teórico, baseado no "que fazer". Além de ensinar o que saber, é preciso lembrar-se de ensinar como agir.

Para aproximar a teoria da prática, sugere-se uma mudança na abordagem dos conteúdos dentro da sala de aula, como a inclusão de situações-problemas e o uso de metodologias ativas com os estudantes. Adaptar a teoria para a prática pode diminuir a distância entre ambas e preparar melhor os estudantes para a realidade do trabalho.

Uma limitação deste trabalho foi a de não entrevistar os professores quanto às metodologias utilizadas, pois, somente através dos planos de ensino, não é possível verificar a abordagem para cada conteúdo ou aula; logo, algumas das atividades citadas como exemplos ou sugestões podem já ser desenvolvidas pelos docentes da área. Sugere-se que sejam realizadas novas pesquisas para aprofundar a discussão.

O planejamento de cursos e disciplinas deverá considerar as legislações que regem a profissão, os requisitos legais exigidos pelo ambiente de trabalho, as normativas do sistema de ensino e, também, a realidade da prática. Numa área como a alimentação coletiva, a vinculação da teoria com a prática é especialmente necessária. Não é uma tarefa fácil, pois envolve um novo olhar sobre o ensino e um novo planejamento de cada conteúdo. No entanto, o esforço em melhorar o ensino qualifica os profissionais que atuarão, em breve, em prol da sociedade.

\section{REFERÊNCIAS}

ALBANESE, Mark A.; MITCHELL, Susan. Problem-based learning: A review of literature on its outcomes and implementation issues. Academic Medicine, Washington, v. 68, n. 1, p. 52-52, fev. 1993. Disponível em: https://www.researchgate.net/profile/Mark_Albanese/publication/14751207_Problembased_learning_A_review_of_literature_on_its_outcomes_and_implementation_issues/link s/560003a408aeba1d9f844a82/Problem-based-learning-A-review-of-literature-on-itsoutcomes-and-implementation-issues.pdf. Acesso em: fev. 2019.

ALBUQUERQUE, Verônica S. et al. A integração ensino-serviço no contexto dos processos de mudança na formação superior dos profissionais da saúde. Revista Brasileira de Educação Médica, Rio de Janeiro, v. 32, n. 3, p. 356-362, jul./set. 2008. DOI: http://dx.doi.org/10.1590/S0100-55022008000300010.

BARDIN, Laurence. Análise de Conteúdo. São Paulo: Martins Fontes, 1979. BRASIL. Ministério da Educação. Lei no. 9.394, de 20 de dezembro de 1996. Lei de Diretrizes e Bases da Educação Nacional. Brasília, 20 dez. 1996. 
BRASIL. Ministério da Educação. Resolução CNE/CES 5, de 7 de novembro de 2001. Conselho Nacional de Educação. Institui diretrizes curriculares nacionais (DCNs) do curso de graduação em nutrição. Diário Oficial da União. Seção 1, p. 39, 9 nov. 2001.

BRASIL. Resolução de Diretoria Colegiada (RDC) no 216, de 15 de setembro de 2004. Dispõe sobre Regulamento Técnico de Boas Práticas para Serviços de Alimentação. Diário Oficial da União. 15 set. 2004.

BONWELL, Charls C.; EISON, James A. Active learning: creating excitement in the classroom. Eric Digests, Publication Identif. ED340272, 1991. Disponível em:

http:// www.ericdigests.org/1992-4/active.htm. Acesso em: 14 fev. 2014.

CONSELHO FEDERAL DE NUTRICIONISTAS (CFN). Resolução CFN no 418, de março de 2008. Dispõe sobre a responsabilidade do nutricionista quanto às atividades desenvolvidas por estagiários de nutrição e dá outras providências. Diário Oficial da União. Seção I, p. 109-110. Brasília, 9 mar. 2008.

CONSELHO FEDERAL DE NUTRICIONISTAS (CFNa). Resolução CFN n‥ 600, de 25 de fevereiro de 2018. Dispõe sobre a definição das áreas de atuação do nutricionista e suas atribuições, indica parâmetros numéricos mínimos de referência, por área de atuação, para a efetividade dos serviços prestados à sociedade e dá outras providências. Brasília, 2018. Disponível em: http://www.cfn.org.br/wp-content/uploads/resolucoes/Res_600_2018.htm. Acesso em: fev. 2019.

CONSELHO FEDERAL DE NUTRICIONISTAS (CFNb). Perfil dos nutricionistas do Brasil. Brasília, 2018. Disponível em: http://pesquisa.cfn.org.br/. Acesso em: maio 2019.

CONSELHO FEDERAL DE NUTRICIONISTAS (CFNc). Código de Ética do Nutricionista. Resolução no 599, de 25 de fevereiro de 2018. Dispõe sobre o Código de Ética do Nutricionista e dá outras providências. Disponível em: http://www.cfn.org.br/wpcontent/uploads/resolucoes/Res5992018.htm. Acesso em: fev. 2019.

EMILAURA, Alves et al. Nutricionistas egressos da Universidade Federal de Santa Catarina: áreas de atuação, distribuição geográfica, índices de pós-graduação e de filiação aos órgãos de classe. Revista de Nutrição, Campinas, v. 16, n. 3, p. 295-304, jul./set. 2003. DOI: http://dx.doi.org/10.1590/S1415-52732003000300007.

FEIX, Monique; POLL, Fabiana Assmann. Perfil profissional de nutricionistas egressos da Universidade de Santa Cruz do Sul. Cinergis, Santa Cruz do Sul, v. 16, n. 4, p. 242-248, out. 2015. DOI: http://dx.doi.org/10.17058/cinergis.v16i5.6319.

RAVITZ, Jason. Introduction: Summarizing findings and looking ahead to a new generation of PBL research. Interdisciplinary Journal of Problem-based Learning, West Lafayette, v. 3, n. 1, p. 2, 2009. DOI: https://doi.org/10.7771/1541-5015.1088. 
MILLIS, Barbara.; COTTELL, JUNIOR, Philip. Cooperative learning for higher education faculty. Phoenix, AZ: Oryx Press, 1998.

MINAYO, Maria Cecília de Souza (org.). Pesquisa social: teoria, método e criatividade. 6. ed. Petrópolis: Vozes, 1996.

RIO GRANDE DO SUL. Portaria no 78, de 28 de janeiro de 2009. Aprova a lista de verificação em boas práticas para serviços de alimentação, aprova normas para cursos de capacitação em boas práticas para serviços de alimentação e dá outras providências. Secretaria da Saúde do Estado do Rio Grande do Sul. Diário Oficial/RS, v. 30, p. 2078-3009. 2009.

RODRIGUES, Karla Meneses; PERES, Frederico; WAISSMANN, William. Condições de trabalho e perfil profissional dos nutricionistas egressos da Universidade Federal de Ouro Preto, Minas Gerais, entre 1994 e 2001. Ciência \& Saúde Coletiva, Manguinhos, v. 12, n. 4, p. 10211031. 2007. DOI: http://dx.doi.org/10.1590/S1413-81232007000400023. Disponível em: https://www.scielosp.org/scielo.php?pid=S1413-81232007000400023\&script=sci_arttext. Acesso em: fev. 2019.

SILVA, Rafael Rodrigues; SANTOS, Raquel; DE AMORIM, Jamile Ferro. A teoria e a prática caminhando de mãos dadas: a experiência docente no eixo Integração Ensino, Serviço e Comunidade. Revista Docência do Ensino Superior, Belo Horizonte, v. 8, n. 1, p. 179-188, jul. 2018. DOI: https://doi.org/10.35699/2237-5864.2018.2443. Disponível em:

https://periodicos.ufmg.br/index.php/rdes/article/view/2443. Acesso em: fev. 2019.

UNIVERSIDADE FEDERAL DO PAMPA (Unipampa). Projeto Pedagógico do Curso de Nutrição. Itaqui, 2012. Disponível em:

http://cursos.unipampa.edu.br/cursos/nutricao/files/2013/07/PPC_NUTRI\%C3\%87\%C3\%83 O-UNIPAMPA.pdf. Acesso em: fev. 2019.

VAZ, Célia Silvério. Restaurantes: controlando custos e aumentando lucros. Brasília: Metha, 2006. p. 196. 


\section{Joice Trindade Silveira}

Professora no curso de Nutrição na Universidade Federal do Pampa nas áreas de Gestão de Unidades de Alimentação e Nutrição e Deontologia. Doutora em Educação em Ciências (PPGECQVS/UFRGS), mestre em Microbiologia Agrícola e do Ambiente (UFRGS) e graduada em Nutrição (UFRGS). Desenvolve pesquisas na área de alimentação coletiva e ensino em Nutrição.

joicetsilveira@gmail.com

\section{Karina Wermuth}

Estudante de Nutrição na Universidade Federal do Pampa - Unipampa. karinawermuth.kw@gmail.com

\section{Ingrid Jesien}

Estudante de Nutrição na Universidade Federal do Pampa - Unipampa.

ingridjesien@hotmail.com 